\title{
LA PERSONA JURÍDICA COMO BENEFICIARIO DE DERECHOS FUNDAMENTALES Y PROTECCIÓN CONSTITUCIONAL EN LA JUSTICIA HONDUREÑA
}

\section{Mauricio José C. Rosales ${ }^{1}$ \\ DOI: https://doi.org/10.5377/Ird.v41i1.10496}

\section{RESUMEN:}

Los derechos fundamentales surgen como resultado de la pugna social de los ciudadanos de un Estado por aspirar a un mejoramiento efectivo de las condiciones humanas en las que viven. De esta manera, los derechos constitucionales surgen con la creación de las mismas Constituciones formales, pues su construcción histórica y democrática a través de la experiencia de los procesos constituyentes en EEUU y Francia, permitieron el reconocimiento y establecimiento de un catálogo mínimo de derechos que sirven como mecanismo de garantía al individuo y que establece límites al ejercicio del poder, sean estos públicos o privados.

En ese sentido, el presente artículo tiene por objeto determinar si la persona jurídica es beneficiaria o no de derechos fundamentales en Honduras, para lo cual se ha tomado en consideración realizar un análisis sobre el origen, naturaleza y fin de los derechos fundamentales, examinando a su vez la doctrina constitucional sobre la teoría de atribución de titularidad de estos derechos, para así observar la realidad jurídico - constitucional hondureña a la luz de los principios y fines del texto fundacional, debatiendo sobre las antinomias presentes en la relación antagónica de titularidad de derechos fundamentales entre la persona natural y jurídica.

PALABRAS CLAVE: Derecho Constitucional, Derechos Fundamentales, Persona Jurídica, Persona Humana, Dignidad.

Fecha de recepción: 30 de agosto de 2020 Fecha de aprobación:09 de noviembre de 2020

1 Abogado egresado de la Universidad Nacional Autónoma de Honduras. Maestrante del posgrado en Derecho Constitucional por la Universidad de Valencia, España. Asistente Legal del Consultorio Jurídico Gratuito, unidad académica adscrita a la Facultad de Ciencias Jurídicas de la Universidad Nacional Autónoma de Honduras. - Correo Electrónico: mauricio.cantor@unah.edu.hn 


\title{
THE LEGAL PERSON AS A BENEFICIARY OF FUNDAMENTAL RIGHTS AND CONSTITUTIONAL PROTECTION IN HONDURAN JUSTICE
}

\author{
Mauricio José C. Rosales ${ }^{2}$ \\ DOI: https://doi.org/10.5377/Ird.v41i1.10496
}

\begin{abstract}
Fundamental rights emerge as a result of the social fight of the citizens of a State seeking an effective improvement of the human conditions in which they live. Therefore, constitutional rights arise from the creation of formal Constitutions, since their historical and democratic construction through the experience from constituent processes in the US and in France allowed for the recognition and establishment of a minimum catalogue of rights that operate as a mechanism of guarantees for each individual, establishing at the same time limitations over the public or private exercise of power.
\end{abstract}

In that regard, this article aims to determine whether or not legal entities in Honduras are beneficiaries of fundamental rights, for which purpose an analysis has been considered to determine the origin, nature and purpose of fundamental rights, along with an assessment of the constitutional doctrine of the theory of attribution of entitlement to such rights, in order to observe our own constitutional and legal reality in view of the principles and purposes of our founding text, debating about the existing antinomies in the antagonistic relationship in the sphere of entitlement to fundamental rights between individuals and legal entities.

KEYWORDS: Constitutional Law, Fundamental Rights, Legal Person, Human Person, Dignity.

Date received: August 30, 2020 Approval date: November 09, 2020

2 Lawyer graduated from the National Autonomous University of Honduras. Master's intern of Constitutional Law from the University of Valencia, Spain. Legal assistant of the Free Legal Office unit attached to the Faculty of Legal Sciences of National Autonomous University of Honduras. - E-mail: mauricio.cantor@unah.edu.hn 


\section{INTRODUCCIÓN}

Los derechos fundamentales son el conjunto de prerrogativas de carácter iusnaturalista inherentes, mínimos y esenciales a la persona que encuentran su razón axiológica en la dignidad humana; por ende, su construcción histórica es el resultado de la pugna social de los ciudadanos de un Estado por aspirar a un mejoramiento efectivo de las condiciones humanas en las que viven. Por tal motivo, la fuerza normativa de los derechos fundamentales tiene una construcción democrática por medio de los procesos constituyentes; en consecuencia, su origen se remonta a la creación de las mismas constituciones formales.

En ese sentido, el elemento de la titularidad de los derechos constitucionales procura responder quiénes o qué sujetos poseen derechos fundamentales. Esto ha derivado en un debate teórico - jurídico que confronta a la persona natural y jurídica, llegando incluso a plantear esta problemática ante las instancias internacionales, en donde se analiza si únicamente la persona natural puede ejercitar derechos humanos o, si, por el contrario, estos derechos son extensibles a la persona jurídica (Opinión Consultiva OC-22/16, 2016).

De esta manera, el presente artículo tiene por objetivo determinar si la persona jurídica es beneficiaria o no de derechos fundamentales de acuerdo al ordenamiento constitucional y legal en Honduras, para lo cual, se realizará un análisis sobre el origen, naturaleza y fin de los derechos fundamentales, examinando a su vez la doctrina constitucional sobre los diversos elementos que concurren para determinar la titularidad de estos derechos y; de este modo, observar la realidad jurídico - constitucional hondureña a la luz de sus principios, fines y hermenéutica, procurando, a su vez, debatir sobre las antinomias presentes en la regulación legal y desarrollo jurisprudencial en torno a la protección de derechos fundamentales de la persona jurídica en la justicia constitucional de Honduras.

Atendido lo anterior, la construcción teórica de la noción de los derechos fundamentales estaría marcada por dos grandes momentos históricos del constitucionalismo. El primero referente a su concreción formal por medio de los procesos constituyentes iniciados en Estados Unidos de América (EEUU) y Francia, en donde se reconocería un catálogo mínimo de derechos esenciales para el hombre y; el segundo, el cual ocurriría en la Alemania post segunda guerra mundial, en donde se aportaría el valor - principio de la dignidad como eje central de la actividad socio - estatal y la noción de doble dimensión que cumplen estos derechos en la vida jurídico - política de un Estado. Ciertamente estos elementos serían el epítome del Constitucionalismo latinoamericano vivido en el periodo post dictaduras militares en la década de los 80's.

En tal sentido, para determinar los sujetos que son beneficiarios de estos derechos se deben analizar las técnicas de atribución de titularidad utilizadas por el poder constituyente, en virtud que la titularidad es un elemento que otorga y reconoce un estatus normativo o condición jurídica a un sujeto frente al Estado. Es así que, en el caso hondureño, el poder originario 
utilizaría técnicas innominadas de atribución, estableciendo derechos fundamentales en la parte dogmática del texto fundacional sin indicar quien será su beneficiario, en otros tantos casos empleó una técnica de atribución omnicomprensiva, indicándolo como "persona". Lo anterior, ciertamente deriva en una multiplicidad interpretativa producto de la falta de claridad y certeza técnica del Constituyente, por lo cual, en el presente estudio, se propende responder a este silencio del soberano sobre el sujeto destinatario al cual se refieren estas disposiciones.

De esta forma, el presente estudio científico nace como resultado de la lectura, estudio y observación de las Sentencias de Amparo emitidas por la Sala de lo Constitucional de la Corte Suprema de Justicia de Honduras, en donde se identificó que la Sala mantenía una línea jurisprudencial con jerarquía reiterativa de tramitación, sustanciación y protección de derechos fundamentales de la persona jurídica.

Lo anterior, llevó a cuestionarse sobre los fundamentos legales utilizados por la Sala para brindar la tutela de derechos de rango constitucional a la persona moral. Por tal motivo, se inició este proceso investigativo con ánimo de dar respuesta si de acuerdo al ordenamiento constitucional y legal en Honduras es posible que la persona jurídica goce de derechos fundamentales $\mathrm{y}$, por extensión, sea sujeto de protección constitucional en la justicia hondureña.

Asípues, el presenteestudio se justifica sobre la base del interés de aportar conocimiento al mundo de la ciencia del derecho, para así generar las bases de un debate jurídico en torno a cuestionar si la persona jurídica puede o debe ser sujeto de derechos constitucionales en Honduras.

\section{METODOLOGÍA}

Tomando en consideración los objetivos planteados y con la finalidad de dar respuesta a la situación problemática formulada, la presente investigación es de tipo dogmático, basado en un modelo epistemológico de racionalismo jurídico, toda vez que el presente estudio descansa en la observación teórica sobre la titularidad de los derechos fundamentales de la persona jurídica, en donde se propende resolver la incógnita propuesta a través del análisis y raciocinio de los principios y métodos de interpretación constitucional, obviando por tal motivo cualquier observación del orden experimental.

Todo lo anterior se fundamenta en los parámetros y procesos del método descriptivo, analítico y explicativo, por cuanto la investigación traza la observación sistemática del origen de los derechos fundamentales, su finalidad y técnicas de titularidad, para así mostrar la situación actual de la regulación normativa hondureña y el desarrollo jurisprudencial en relación al tema objeto de estudio, procurando de esta manera sustentar de forma clara y precisa las razones que permitan determinar si la persona jurídica es beneficiaria o no de derechos fundamentales y protección constitucional en el modelo de justicia hondureño. 


\section{ORIGEN, NATURALEZA Y FINALIDAD DE LOS DERECHOS FUNDAMENTALES}

Los derechos fundamentales al encontrarse en la categoría dogmática del derecho constitucional, se conciben como el conjunto de prerrogativas de carácter iusnaturalistas inherentes, mínimos y esenciales a la persona que encuentran su razón axiológica en la dignidad humana. En consecuencia, la Constitución es el elemento de conexión y sentido para los derechos fundamentales, por cuanto vincula al derecho y a la política de un país, fijando los valores y principios rectores sobre los cuales se funda un Estado (Villalon Cruz, 1989).

Dicho lo anterior, la fuerza normativa de los derechos fundamentales tiene su origen en la creación de las mismas Constituciones formales, pues su construcción democrática a través de los procesos constituyentes se erige como un instrumento de optimización de la actividad política que permite la efectividad material de los postulados constitucionales y, a su vez, sirven como mecanismo de defensa para los ciudadanos, pues establece límites a los poderes, sean estos públicos o privados (Landa, 2010).

En ese sentido, la construcción histórica sobre la noción de los derechos fundamentales estaría marcada por dos grandes revoluciones en el ámbitojurídico. La primera, caracterizada por el reconocimiento de libertades mínimas y esenciales en los textos fundacionales de los nacientes Estados democráticos, como, por ejemplo, el establecimiento del denominado Bill of Rights a nivel federal en los EEUU en el año 1791, junto con sus respectivas enmiendas constitucionales proferidas en el periodo post guerra civil a mediados del siglo XIX (Carbonell, 2011). Paralelamente, en Francia se constituiría un modelo de derecho moderno basado en el individuo como sujeto de derechos y obligaciones, proceso que sería materializado por medio de la Declaración de Derechos del Hombre y del Ciudadano de 1789, cristalizando de esta forma la consigna popular de la revolución francesa: "Liberté, Égalité, Fraternité” (Landa, 2010).

Este primer momento, se caracterizaría por la manifestación expresa de las asambleas constituyentes de reconocer un catálogo mínimo de derechos esenciales para los individuos, los cuales, sin lugar a dudas, tendrían un rol preponderante en la vida social y política del Estado. Esta primera noción de los derechos fundamentales estaría marcada por una dimensión unilateral, en el sentido que estos preceptos jurídicos eran considerados únicamente como derechos subjetivos, es decir, que garantizaban al individuo un estatus legal de libertad e igualdad en el ámbito de la existencia y servían como límites al poder público; por ello, en caso de existir quebrantamiento a estos derechos por arbitrariedades de alguna autoridad, el interesado podría recurrir estos actos ante un Juzgador por medio de una garantía constitucional que más tarde sería conocida como el Amparo, a través de la cual el funcionario judicial protegería el bien jurídico conculcado y podría, a su vez, precisar, definir, ampliar o incluso redefinir el contenido del derecho fundamental en cuestión (Segado Fernandez, 1993). 
El segundo momento histórico ocurriría en la Alemania post II guerra mundial, con la promulgación de la denominada Ley Fundamental de Bonn, cuyo contenido en su artículo 1.1 declara que: "La dignidad humana es intangible". Esto daría lugar a que el Tribunal Constitucional Federal alemán realizara un desarrollo hermenéutico sobre los conceptos "dignidad humana" y "derechos fundamentales", aportando al mundo de la ciencia jurídica que estos dos conceptos se encuentran vinculados entre sí, en cuanto y en tanto la dignidad constituye el valor principio supremo y rector del ordenamiento constitucional; por ende, la finalidad de los derechos fundamentales es la protección de la dignidad del individuo (Segado Fernández, 1996).

Lo anterior conllevaría a una evolución de paradigma sobre el alcance de la dimensión de los derechos constitucionales, en virtud que a partir de las consideraciones alemanas estos derechos serian valorados e interpretados como normas con una doble dimensión o efecto jurídico; por un lado, considerándolos como derechos subjetivos $\mathrm{y}$, por otro lado, como prerrogativas de carácter objetivo que proyectan su luz dotando de contenido al resto del ordenamiento jurídico secundario de un país, y, procurando encaminar la actividad de la autoridad pública a tomar decisiones que aseguren un mayor grado de efectividad para la plena realización de estos derechos (Sentencia BVerfGE, 1958).

En otro orden de ideas, en América Latina durante la segunda mitad del siglo XX y con la caída de las dictaduras militares y civiles, se incorporaría al constitucionalismo latinoamericano el modelo alemán de respeto y defensa de la persona humana y su dignidad como eje central de la actividad estatal ${ }^{3}$; por tanto, la cristalización y vinculación de estos dos aspectos jurídico - normativos en los textos constitucionales, marcan un horizonte social y temporal para las naciones, en virtud que la dignidad es la fuente de los derechos esenciales del hombre y que permite, a su vez, a los individuos por medio de su voluntad y sentidos definir el tipo y forma de vida que desean para poder alcanzar la plena felicidad; en cambio, para el Estado, impone una carga negativa y positiva de comportamiento, pues, por un lado, tendrá que abstenerse intervenir arbitrariamente en el goce de estos derechos y; por otro lado, deberá crear las condiciones necesarias para que las personas puedan obtener esta aspiración (Landa, 2010).

Por tanto, como puede apreciarse, la construcción histórico - jurídica de los derechos fundamentales es el resultado de la pugna social de los ciudadanos de un Estado por aspirar a un mejoramiento efectivo de las condiciones humanas en las que viven. Por tal motivo, la naturaleza jurídico - pragmática de estos derechos toma como base fundamental la protección de la dignidad humana, pues a través de este principio unificador es donde el ser humano puede alcanzar su plena realización en condiciones de igualdad, bienestar, justicia y paz social.

3 Art. 59 de la Constitución de la República de Honduras: "[...] La dignidad humana es inviolables [...]”; Art. 4 de la Constitución Política de la República de Guatemala: “[ ...] En Guatemala todos los seres humanos son libres e iguales en dignidad y derechos [...]”; Art. 5 de la Constitución Política de la República de Nicaragua: "Son principios de la nación nicaragüense, la libertad, la justicia, el respeto a la dignidad humana [...]”; Art. 1 de la Constitución Política de la República de Chile: "Las personas nacen libres e iguales en dignidad y derechos $[\ldots]$ ”. 


\section{LA TITULARIDAD DE LOS DERECHOS FUNDAMENTALES Y LA PROTECCIÓN JUDICIAL EN LA DOCTRINA CONSTITUCIONAL.}

La titularidad es uno de los presupuestos de la teoría general de los derechos fundamentales y uno de los elementos centrales de la relación jurídica iusfundamental. Como presupuesto de la teoría, la titularidad procura responder sobre quienes o qué sujetos poseen derechos fundamentales. En consecuencia, desde sus orígenes, la titularidad de los derechos fundamentales ha sido entendida histórica y tradicionalmente como un atributo que gozan única y exclusivamente las personas naturales, físicas o de carne y hueso, pues su fundamento radica en la dignidad humana que estos poseen (Contreras Vásquez, 2017).

En ese orden de ideas, el concepto de titularidad de los derechos fundamentales puede definirse según Pablo contreras (2017) como: "El estatus normativo o condición jurídica en virtud de la cual se constituye un sujeto de derecho que es beneficiado con la protección del derecho, igualdad o libertad que un ordenamiento jurídico reputa como derecho fundamental" (p. 120). Se trata, entonces, de una posición normativa que un ordenamiento jurídico reconoce o atribuye a un sujeto.

Atendido lo anterior, el ordenamiento jurídico efectúa esta decisión de atribución bajo el mandato de igualdad; de manera tal que las normas que confieran derechos fundamentales deberán estar escritas en sentido general, es decir, sin exclusiones o diferenciaciones injustificadas en razón de sexo, ideología política, raza, color, posición económica o cualquier otra análoga. En tal sentido, el término "persona" ha sido utilizado para categorizar la atribución de derechos constitucionales y, por extensión, su respectivo ejercicio; por ello, la discusión de atribución de titularidad versa sobre los distintos caracteres o propiedades que permiten configurar un estatus de personalidad, tales como la capacidad de voluntad, autoconsciencia y valor moral de un individuo (Contreras Vásquez, 2017).

Sin embargo, bajo este contexto, los términos "titularidad" y "persona" no son dos conceptos implícitos en su contenido, es decir, que el vocablo "personalidad" no atribuye automáticamente derechos fundamentales. Por tanto, la determinación de quienes o qué sujetos tienen derechos constitucionales $\mathrm{y}$ por tanto son titulares y pueden ejercitar los mismos, es una decisión normativa que adopta cada ordenamiento jurídico, ya sea en su jerarquía constitucional o legal; dicho de otra manera, la atribución de titularidad de un derecho requiere su reconocimiento en el ordenamiento jurídico de un país (Contreras Vásquez, 2017).

Bajo esa misma lógica, los textos constitucionales, en general, asignan la titularidad de los derechos fundamentales mediante una técnica amplia de atribución, empleando terminologías tales como: "personas", "todas las personas", "individuos", "hombre", "mujer" o incluso, en algunas ocasiones, se utiliza el gentilicio del país en cuestión. En cualquiera de estas circunstancias, dichos términos evocan simplemente una noción omnicomprensiva 
respecto del beneficiario del derecho fundamental. Asimismo, existen casos concretos en donde el texto constitucional o una norma de orden legal atribuye titularidad a la persona jurídica ${ }^{4}$, en cuyo caso se entenderá que el derecho podrá ser ejercitado también por este sujeto intangible.

No obstante, en aquellos casos en que se emplee terminologías amplias de atribución de titularidad y no exista ninguna previsión de orden constitucional o legal que impida a la persona jurídica ser sujeto de este tipo de derechos, los Estados han optado, por medio del desarrollo jurisprudencial, en reconocer quelapersonajurídica es beneficiariodeciertos derechos constitucionales de forma implícita, para lo cual han retomado los dos criterios hermenéuticos desarrollados por el Tribunal Constitucional Federal Alemán, a saber: 1) La naturaleza del derecho fundamental debe o puede ser aplicable a una persona jurídica y; 2) El sujeto que ostenta la personalidad jurídica debe encontrarse dentro del ámbito del derecho privado, pues las entidades de derecho público, por su propia naturaleza están excluidas, ya que la concepción de derechos fundamentales se construye bajo la noción de protección del individuo frente al ejercicio de los poderes públicos (Contreras Vásquez, 2017).

Esta doctrina legal se fundamenta sobre la consideración de reconocer que las actividades de las organizaciones que fundan las personas

4. Art. 19 numeral 3 Ley Fundamental de la República Federal de Alemania "Los derechos fundamentales rigen también para las personas jurídicas con sede en el país, en tanto por su propia naturaleza sean aplicables a las mismas". Art. 12 numeral 2 Constitución de Portugal: "Las personas colectivas gozarán de los derechos y los deberes compatibles con su naturaleza". naturales responden a los intereses y fines definidos por los socios o directivos; por ende, es lógico pensar que si el objetivo y función de los derechos fundamentales es la protección del individuo, sea como tal o en colectividad, servirán también para proteger los fines de las organizaciones que las mismas personas naturales han constituido, en tanto y en cuanto se empleen para defender la propia existencia e identidad de la persona jurídica (Casas de Ignacio y Toller M., 2015).

Pese a estas consideraciones, $\mathrm{y}$, con ánimo de realizar una breve crítica jurídica al respecto, la fundamentación y/o motivos utilizados para justificar la titularidad de derechos fundamentales por parte de las personas jurídicas, resulta en explicaciones muy ambiguas y poco contundentes, en virtud que existe una falta de claridad respecto a los criterios, parámetros o subestándares que deberán analizarse para determinar cuando la naturaleza de un derecho permite ser aplicable también a la persona moral. Lo anterior, radica en que el criterio de aplicabilidad es una consecución de la naturaleza del derecho, esto implica que para valorar, interpretar y determinar cuándo un derecho fundamental es aplicable a la persona jurídica, esto presupone retomar el valor intrínseco de la dignidad del individuo como punto de partida y corolario de la finalidad de los derechos fundamentales.

Bajo esa misma lógica, esto derivaría en analizar cada derecho desde la esfera de su relación o vínculo con la dignidad humana, lo cual en el pensamiento del filósofo alemán Immanuel Kant presuponía que el fundamento de la dignidad humana radica en la naturaleza racional del ser humano, es decir, su autonomía 
de voluntad y facultad de determinarse por sí mismo; por ende, los seres cuya existencia depende de la naturaleza y no de su voluntad tienen un valor relativo como medios y por eso se llaman cosas, mientras que los seres racionales se llaman personas (Rey, 2014).

Por tanto, los derechos fundamentales que encuentran su origen intrínseco en la dignidad humana, únicamente podrán ser ejercitados por el ser humano, esto debido a su capacidad de ser racional dotado de autoconsciencia, sentidos, sentimientos, valores, creencias $\mathrm{y}$ voluntad propia para dirigir su vida y decisiones; en consecuencia, equiparar los intereses de una persona jurídica al mismo nivel de la dignidad humana para justificar una protección constitucional de derechos de la persona jurídica, es desnaturalizar per se el objeto y fin de los derechos fundamentales, ya que en caso de que una persona moral alegue la existencia de una vulneración de un derecho constitucionalizado, lo único que ve afectado en el plano material son sus interés como organismo y no un principio rector del orden constitucional como la dignidad humana.

\section{LA PERSONA JURÍDICA: NATURALEZA Y DERECHOS SEGÚN EL ORDENAMIENTO JURÍDICO HONDUREÑO}

La persona jurídica o también denominada persona moral, es el resultado histórico de la naturaleza humana de organizarse y relacionarse de forma interactiva con los mismos de su especie en una sociedad democrática, para así cumplir con los fines conjuntos que se proponen ${ }^{5}$, pues tal y como

5 V.gr. La finalidad de los Estados es el bien común de toda la afirma Diez-Picazo y Gullón Ballesteros (2012): "el hombre por sí solo no puede alcanzar muchos de los fines que su propia personalidad postula, porque superan inexorablemente su capacidad individual y necesita unirse con otros para conseguirlos" (p. 503).

Atendido lo anterior, para poder generar un concepto aproximado de lo que debe comprenderse como persona jurídica, debe tomarse en consideración los elementos que interactúan para que este individuo del derecho pueda existir, es decir, aquellos componentes materiales que permiten la constitución de este sujeto del derecho, así podemos mencionar: 1) la concurrencia de un conjunto de personas con voluntad de asociarse y que se encuentren debidamente organizadas, 2) existencia de intereses comunes lícitos de las personas que la pretenden constituir y; 3) finalidad lucrativa o no.

Así pues, tomando en consideración estos elementos y con ánimo de realizar una aproximación conceptual prima facie, puede decirse que la persona jurídica es aquel individuo intangible conformado por dos o más personas civilmente capaces que se unen para manifestar, por medio de este nиеvo sujeto, su voluntad colectiva y así perseguir los intereses comunes legalmente permitidos por el ordenamiento jurídico de un país, sean estos con fines o no de lucro. De esta manera, como puede observarse, la persona jurídica es una creación del derecho, en la cual la ley reconoce con personalidad independiente y

población. El caso de las asociaciones y fundaciones la finalidad se establecerá de acuerdo al contrato de sociedad o estatutos, respectivamente y; estos podrán ser con fines o no de lucro. 
diferenciada a la de cada uno de sus miembros (personas naturales) que la componen y le dota de capacidad legal suficiente para poder ejecutar actos que generen obligaciones y desplieguen efectos jurídicos para con las demás personas físicas o morales con las que se interrelaciona.

En función de lo planteado, surge entonces el problema de determinar cuáles son los derechos que goza una persona jurídica en el ámbito normativo del Estado de Honduras. Para dar respuesta a este planteamiento, resulta imprescindible identificar la postura doctrinaria sobre la naturaleza de la persona jurídica por la que ha decidido decantarse el legislador hondureño y plasmarla en la creación del Código Civil. Así, destacan la teoría de la ficción y la realidad, las cuales se erigen sobre la base del pensamiento de reconocer la existencia de la persona jurídica como sujeto de derechos y obligaciones independiente de las personas físicas que la integran, pero se diferencian en cuanto a su matiz de percepción en lo relativo a su reconocimiento como personalidad y la delimitación de derechos que posee este sujeto.

\section{a) Teoría de la Ficción}

Para esta corriente de pensamiento, la persona jurídica goza de similares obligaciones y derechos que la persona física, pues esta similitud se fundamenta en la noción de que la persona moral carece de voluntad y sentidos, pues materialmente son las personas físicas que la conforman quienes determinan el actuar de este individuo ficticio; por tanto, las personas jurídicas no ejercen todos los derechos subjetivos debidamente reconocidos en el estamento legal de un país (Capilla Roncero, 1984); al contrario, serán únicamente aquellos regulados y debidamente delimitados por la ley.

Asimismo, el reconocimiento de su personalidad deberá darse por medio de un procedimiento legal en el que se deberá cumplimentar con los requisitos y etapas normativas instruidas previamente por el legislador, para así dotar de validez la constitución de la persona jurídica en cuestión, dicho de otra manera, el Estado es el único capaz de crear estas entidades dentro de su facultad de "potencia soberana" (Capilla Roncero, 1984).

\section{b) Teoría de la Realidad}

En contraposición a la tesis de la ficción y, sin ahondar en las subcategorías desarrolladas dentro de esta doctrina, esta tesis propugna que la persona jurídica es una realidad concreta preexistente a la voluntad de las personas físicas (Capilla Roncero, 1984); en consecuencia, la persona moral funciona como un organismo autónomo con voluntad propia, la cual es fijada a su vez, por la voluntad colectiva de las personas naturales que la integran; por tanto, para esta teoría, la persona jurídica goza de todos los derechos subjetivos sin ningún tipo de delimitación o restricción. Aunado a esto, esta corriente de pensamiento se diferencia también en cuanto al acto de reconocimiento de la persona jurídica, ya que, para esta doctrina, el reconocimiento que hace el Estado y el derecho tiene un valor meramente declarativo y no constitutivo. 
En ese orden de ideas, el Código Civil hondureño en su artículo 56 comienza desglosando los distintos sujetos que son considerados como personas jurídicas, y, aún más importante, regula el momento en que comienza su existencia legal como persona moral. Así, en los términos empleados por el legislador en dicho cuerpo legal, la persona jurídica tendrá su génesis hasta que se autorice su constitución por medio de disposición legal, resolución o acto de una autoridad competente; por ende, como puede apreciarse, el Estado es quien controla la creación de estos entes y, solamente a través de la sustanciación del procedimiento previamente instruido en la norma jurídica, es cuando el derecho es capaz de crear o disolver estos entes.

Por otro lado, el artículo 59 de la citada norma sustantiva delimita los derechos que goza la persona jurídica, siendo estos los mismos que se le reconocen a la persona natural en sentido general, por cuanto y en tanto tienen la capacidad de adquirir bienes, tomar y conservar la posesión de ellos, constituir servidumbres, recibir usufructos, herencias, legados o donaciones, e intentar acciones civiles o criminales que le incumban, salvo las disposiciones constitucionales.

De esta forma, tomando en consideración los elementos que suministra el ordenamiento jurídico hondureño, puede apreciarse que en Honduras la naturaleza de la persona jurídica se decanta por la teoría de la ficción, en virtud que se cumplen con las dos características significativas que postula esta corriente de pensamiento. Por un lado, la intervención y control del Estado en la creación de estos entes y; por otro lado, la delimitación del conjunto de derechos que goza este individuo: Por tanto, en el ordenamiento jurídico hondureño, la persona jurídica es apreciada como un sujeto carente de voluntad y sentidos propios, ya que son las personas naturales que le integran quienes definen el actuar de este sujeto del derecho.

\section{EL DILEMA ANTINÓMICO SOBRE EL RECONOCIMIENTO DE DERECHOS FUNDAMENTALES A LA PERSONA JURÍDICA EN EL ORDENAMIENTO LEGAL Y EN LA JURISPRUDENCIA HONDUREÑA}

En el caso del modelo hondureño, la teoría de atribución de titularidad de los derechos fundamentales ha sido aplicada a través de un pluralismo terminológico, ya que el poder constituyente empleo técnicas innominadas en donde no especifica concretamente el sujeto beneficiario del derecho fundamental ${ }^{6}$, en otros tantos, siguió un modelo de terminología nominativa con una interpretación omnicomprensiva, delimitándolos como "hombres" o "persona"7 y, en otros casos, siguió un patrón indicativo, designando y reconociendo derechos concretos de rango constitucional a las personas jurídicas. ${ }^{8}$

En ese sentido, como ha podido observarse en los acápites anteriores, surge en esta etapa de análisis un conflicto normativo relativo a la titularidad de los derechos fundamentales de la persona jurídica. Por un lado, el artículo 59

\footnotetext{
6 Artículos 65, 69, 76, 77, 78, 82, 90 entre otros de la Constitución Política de la República de Honduras.

7 Artículos 60, 61, 62, 68, 71, 79, 80, 81, 85, 86 entre otros de la Constitución Política de la República de Honduras.

8 Artículos 80 y 166 de la Constitución Política de la República de Honduras.
} 
del Código Civil en su parte in fine, dispone que la persona jurídica no podrá ejercitar derechos constitucionales y; por otro lado, la Constitución actual y vigente de 1982 reconoce la titularidad y ejercicio expresamente de dos derechos a la persona jurídica, a saber: el derecho de petición y el derecho a fundar centros educativos.

De esta manera, se presenta una antinomia en razón de cronología y jerarquía normativa, ya que el Código Civil es una norma pre constitucional que data de 1906, y, la Constitución vigente de la República de Honduras es de 1982. Por tanto, para resolver esta antinomia debe tomarse en consideración que la Constitución como fuente del derecho posee eficacia directa; en consecuencia, en casos de conflictos entre una norma legal anterior y una disposición constitucional posterior, se deberá resolver mediante la declaración de inconstitucionalidad, en tanto y en cuanto, la disposición legal pre constitucional no pueda conciliarse en razón de su contenido con el nuevo texto constitucional (Viñas Henríquez, 2017).

Lo anterior, resulta como manifestación del Poder Constituyente en aplicación del artículo 376 del texto fundacional que establece: "Todas las leyes, decreto - leyes, decretos, reglamentos, órdenes y demás disposiciones que estuvieren en vigor al promulgarse esta Constitución, continuaran observándose en cuanto no se oponga a ella, o mientras no fueren legalmente derogados o modificados". Esto implica que el citado precepto legal permanecerá y mantendrá su vigencia mientras no se declare su expulsión del ordenamiento jurídico por parte de la
Corte Suprema de Justicia a través de la Sala de lo Constitucional o, por medio de decreto legislativo del Congreso Nacional.

Sin embargo, resulta evidente que parte del texto que compone el artículo 59 del Código Civil no puede conciliarse en razón de su contenido con la actual Constitución, toda vez que la disposición sustantiva del ordenamiento jurídico secundario establece de forma taxativa una restricción ilimitada al ejercicio de todos los derechos constitucionales para la persona jurídica, y; al contrario, como ha podido observarse, el Constituyente en el ejercicio de su potestad soberana decidió otorgar expresamente la titularidad, ejercicio y protección de dos derechos constitucionales a este sujeto intangible. Por ende, el artículo 59 del Código Civil resulta inconstitucional parcialmente, en virtud que el criterio de jerarquía normativa constitucional que reconoce una facultad de ejercicio, se impone frente al ordenamiento jurídico secundario, lo que ameritará la observancia de los órganos de control para su eventual expulsión del ordenamiento jurídico nacional.

Al margen de lo expuesto, si se toma en consideración que la disposición del código Civil resulta invalida parcialmente; en consecuencia, sus efectos al no ser aplicables, da apertura nuevamente al debate sobre la titularidad de la persona jurídica sobre otros derechos fundamentales distintos al de petición y al de fundar centros educativos, lo cual implica analizar aquellos silencios del Constituyente sobre las técnicas omnicomprensivas de titularidad del derecho fundamental, esto permitirá determinar si el resto de los derechos fundamentales en 
Honduras pueden ser ejercitados también por la persona jurídica.

Para resolver esta situación problemática, es pertinente analizar dos principios constitucionales sobre los cuales se funda el Estado de Honduras y retomar la hermenéutica jurídico - constitucional sobre el objeto y fin de los derechos fundamentales. Así, dentro de estas marcas discursivas solemnes que definen el orden jurídico - político que configura el Estado hondureño, destacan los principios de plena realización de la persona humana y la dignidad.

Bajo esa premisa, en aplicación del principio de unidad de la Constitución ${ }^{9}$ y en el marco de la utilización conjunta de los métodos de interpretación gramatical, histórica y finalista; puede observarse, como primer punto, que conforme al sentido corriente que haya de atribuírsele al término "persona", la Real Academia Española la define en su primera acepción como "individuo de la especie humana", mientras que el vocablo "hombre" se entiende como todo ser animado racional, sea este varón o mujer.

Teniendo en cuenta este aspecto inicial, es claro que la lectura literal de las disposiciones omnicomprensivas del constituyente excluye otro tipo de personas distintas a los seres humanos; por ende, no puede pretender aplicarse una interpretación del término "persona" bajo la apreciación y valoración de la clasificación infra constitucional que establece el Código Civil, ya que este último cuerpo normativo no puede ser utilizado

9 Significa que la Constitución deberá interpretarse en sentido armónico con todos sus preceptos. como elemento interpretativo de una norma jerárquicamente superior, en cuanto y en tanto, la naturaleza jurídica, el objeto y ámbito de aplicación del código civil es distinto al de la constitución, así como también la técnica de interpretación constitucional posee sus propios parámetros y criterios hermenéuticos.

En un mismo sentido, bajo el parámetro de la interpretación histórica, puede observarse que los derechos fundamentales surgen en la historia constitucional como prerrogativas mínimas y esenciales con ánimo de proteger al ser humano y su dignidad frente a las arbitrariedades del poder público, $\mathrm{y}$, de esta manera reorientar la actividad del Estado. Por otro lado, si se analiza el objeto y fin de la Constitución, se podrá observar que el Estado hondureño propende la plena realización humana y el respecto a la dignidad del individuo; por tal motivo, en el inicio de la parte dogmática del texto constitucional, en el artículo 59 se establece: "la persona humana es el fin supremo de la sociedad y del Estado y su dignidad es inviolable".

De esta manera, se puede colegir que los derechos fundamentales están orientados a la protección de la dignidad y, a su vez, servir como instrumentos de optimización de la actividad del Estado, para así alcanzar un verdadero ejercicio y goce de esos postulados constitucionales que permitan al ser humano alcanzar esa máxima aspiración de la plena realización.

Sobre esta línea de pensamiento, la Corte Suprema de Justicia a través de la Sala de lo Constitucional ha considerado que uno de los criterios esenciales de la hermenéutica 
constitucional de los derechos fundamentales es el principio pro homine, el cual implica que el derecho debe interpretarse y aplicarse siempre de la manera que más favorezca al ser humano. De esta forma, las autoridades estatales no pueden afectar de ninguna forma la esfera de estos derechos esenciales, ya que es el hombre y no la sociedad, quien tiene la dignidad y; en consecuencia, corresponde a él la titularidad de los derechos fundamentales (Sentencia RI-1343-2014, 2015).

Esta interpretación jurídica dada por la Sala Constitucional ciertamente aporta una respuesta plausible para la solución de la problemática de las técnicas innominadas de atribución de titularidad de derechos fundamentales en la Constitución hondureña, en virtud que la magistratura constitucional considera que la dignidad es un elemento central que se vincula con los derechos fundamentales; por ende, se puede inferir que todo sujeto que ostente dignidad es capaz de ser titular de derechos fundamentales.

Lo anterior, radica en que a través de la dignidad el ser humano es capaz de articular y diseñar por medio de su voluntad y sentidos la forma según la cual desea vivir, siendo acorde a un mínimo de características concretas que permitan su supervivencia, siendo, a su vez, valorado en la singularidad e intangibilidad de sus sentidos morales, para así alcanzar esa máxima aspiración constitucional de la plena realización y; en caso de verse perjudicado en alguna de estas esferas, consecuentemente, verá lesionada su propia dignidad; en cambio, para la persona jurídica, si se considera que se le vulnera un derecho de la misma jerarquía constitucional, únicamente verá lesionado sus intereses.
Sin embargo, la jurisprudencia de la Sala Constitucional también se ha caracterizado por dar trámite y sustanciar acciones de amparo interpuestas por personas jurídicas (públicas o privadas) en favor de sí mismas, ello con la finalidad de tutelar derechos fundamentales distintos a los expresamente reconocidos por el Constituyente, en cuyo caso, la Sala ha procedido en algunos casos a denegar la garantía constitucional ${ }^{10} \mathrm{y}$ en otros tantos otorgando a favor la acción ${ }^{11}$.

Indistintamente de los resultados de las sentencias de amparo que anteceden, la línea jurisprudencial construida por la Sala Constitucional presenta los rasgos semejantes siguientes: 1) La acción pretendida ha procedido contra actuaciones estatales cuya vía procedimental no permite la interposición de otro recurso ordinario para resguardar el orden legal de actuación, 2) los derechos fundamentales alegados por los recurrentes como vulnerados y objeto de análisis son el artículo 82 (derecho de defensa) y el 90 (derecho al debido proceso) y; 3 ) Ninguno de estos fallos analiza, profundiza, conceptualiza, puntualiza o determina criterios jurídicos para determinar la titularidad de los derechos fundamentales de la persona jurídica.

Atendido lo anterior, pese a que el máximo tribunal de justicia no se ha pronunciado de forma concreta sobre la titularidad de los derechos fundamentales, de manera implícita ha conocido, apreciado y entendido que existen circunstancias en donde se han cometido infracciones que atentan contra el ejercicio del derecho de defensa y las formalidades

10 Ver sentencias: AC-828-15, AA-1001-15, AC-509-17.

11 Ver sentencias: AL-322-15, AL-140-17, AC-266-18 
del debido proceso, en donde, a su vez, la persona jurídica se ha visto perjudicada por la decisión del Juzgador, y, ante la imposibilidad de impugnar dicha decisión a través del uso de un recurso para su control por parte de un superior jerárquico, en vista que de acuerdo al contexto del caso, la ley adjetiva aplicable no permite la viabilidad de interposición de recursos ordinarios; por tal motivo, se ha optado por acudir a la vía de amparo.

En ese orden de ideas, se puede colegir que la construcción jurisprudencial de la Sala Constitucional ha entendido como cierto la extralimitación del ejercicio de las funciones de ciertas autoridades, ya sea por acción u omisión, lo cual ha conllevado a una clara infracción jurídica a los principios procesales del ordenamiento jurídico secundario $y$, con ello, el quebrantamiento de la correcta administración de justicia apegada al principio de legalidad y seguridad jurídica que propende la Constitución de la República.

Al margen de lo expuesto, como ha podido observarse a través de los métodos de interpretación constitucional, el análisis de los principios del texto fundacional hondureño y, tomando en consideración el precedente de la magistratura constitucional en su Sentencia RI-1343-14, la dignidad humana se presenta como un elemento común que unifica y vincula el sentido y fin de los derechos fundamentales. Por tanto, la titularidad de un derecho fundamental depende de dos factores, a saber: 1) Factor Objetivo, el cual deberá ser entendido como la facultad o acto de reconocimiento e individualización del sujeto que ejercitará el derecho fundamental y; 2) Factor Subjetivo, lo que implicaría que únicamente la persona humana que ostenta la dignidad puede ejercer un derecho fundamental, esto es debido a su capacidad de autoconciencia, voluntad y sentidos según la cual el ser humano define y dirige la forma según la cual desea vivir.

En otro orden de ideas, para solucionar los problemas procedidos de las infracciones procesales que quebrantan la correcta administración de justicia y atentan contra la seguridad jurídica y legalidad que postula la Constitución, en donde, a consecuencia de estas infracciones, la persona jurídica se ha visto perjudicada, surge necesario crear una postura conciliadora de criterios sin que ello implique una desnaturalización del carácter, objeto y fin de los derechos fundamentales y su titularidad exclusiva de la persona jurídica.

Por tanto, resulta oportuno sugerir la creación de una figura jurídica paralela al amparo, denominada como "acción de control de legalidad" o "acción extraordinaria de control de legalidad", la cual estaría instaurada como mecanismo de defensa extraordinario a favor de la persona jurídica contra actos atentatorios de actos de autoridad pública, en donde se pretenda realizar una fiscalización concreta de la fase procedimental cuando se alegue fundadamente que existe una grave inobservancia en los formalismos del proceso o derecho de defensa que contrarié los principios de legalidad, equidad procesal y seguridad jurídica constitucional, esto permitirá ejercer un control de actuación de la autoridad superior jerárquica y así mantener la seguridad jurídica del ordenamiento legal nacional y proteger los intereses de la persona jurídica. 


\section{CONCLUSIONES}

Habiendo realizado un análisis, descripción y explicación respecto al origen, naturaleza, finalidad, teoría de atribución de titularidad de los derechos fundamentales en la doctrina constitucional y, tras haber examinado las fuentes normativas, jurisprudenciales y la hermenéutica constitucional del contexto jurídico hondureño, para finalizar el presente artículo científico y dar cumplimiento al objetivo fijado en la parte introductoria del mismo, se puede concluir lo siguiente:

Primero: De acuerdo a la regulación constitucional actual, la persona jurídica en Honduras es beneficiaria de derechos fundamentales de forma mediata, esto quiere decir que no ejerce de forma ilimitada todos los derechos consagrados en el texto fundacional, toda vez que el ejercicio de estos derechos de rango constitucional, tales como el de petición y a fundar centros educativos, han sido expresamente reconocidos por el poder constituyente en el pleno ejercicio de su potestad soberana.

Sin embargo, en el caso de aquellos derechos en donde el poder originario empleo técnicas innominadas u omnicomprensivas de titularidad; en estas situaciones, la persona jurídica no será beneficiaria de estos derechos fundamentales, en cuanto y en tanto, los principios rectores del orden constitucional y sus métodos de interpretación conciben que estos derechos tienen como finalidad el respeto, la protección y garantía de la dignidad, la cual se encuentra vinculada de forma intrínseca y natural al ser humano, en donde, a su vez, se procura que la persona natural pueda aspirar a su plena realización, aspectos y/o elementos que solamente el ser humano es capaz de aspirar y cumplir, ya que al ser un ente racional posee autoconciencia, voluntad y sentidos, facultades de las cuales carece la persona jurídica. Por tanto, la titularidad de los derechos fundamentales en los casos en donde el poder Constituyente utiliza el término "persona", se deberá entender que se refiere al ser humano, en virtud que es el único sujeto capaz de ostentar dignidad.

Segundo: La Construcción jurisprudencial de la honorable Corte Suprema de Justicia a través de la Sala de lo Constitucional denota que no existe un criterio unificado y claro respecto a la concreción de la titularidad de los derechos fundamentales. Asimismo, la Sala no ha procedido a profundizar o explicar teórica y conceptualmente las razones del por qué ha procedido a tutelar y/o proteger derechos fundamentales a la persona jurídica distintos a los expresamente otorgados por el Constituyente. Finalmente, se advierte y recuerda que la parte final del artículo 59 del Código Civil permanece vigente, ya que hasta la fecha no se ha declarado su derogación o expulsión del ordenamiento jurídico nacional. En consecuencia, la línea jurisprudencial construida por la Sala Constitucional de la Corte Suprema de Justicia en donde se otorga la tutela de derechos fundamentales a la persona jurídica es contra legem. 


\section{BIBLIOGRAFÍA}

Capilla Roncero, F. (1984). La persona jurídica: funciones y disfunciones. Madrid: Tecnos.

Carbonell,M.(2011).DerechosFundamentales y Activismo judicial en América Latina. En A. E. Canosa Velandia, Derecho Procesal Constitucional (págs. 280-304). Bogotá: Agencia Imperial.

Casas de Ignacio, C. y Toller M., F. (2015). Los derechos humanos de las personas jurídicas. Ciudad de México: Editorial Porrúa, S.A de C.V.

Contreras Vásquez, P. (2017). Titularidad de los derechos fundamentales. En P. Contreras Vásquez, \& C. (. Muñoz Salgado, Manual sobre derechos fundamentales: Teoría general (págs. 119-160). Santiago: LOM Ediciones.

Diez-Picazo, L. y Gullón Ballesteros, A. (2012). Sistema de Derecho Civil. Madrid: Tecnos.

Landa, C. (2010). La fuerza normativa constitucional de los derechos fundamentales. En F. K. AdenauerStiftung, Justicia constitucional y derechos fundamentales (págs. 17-42). Uruguay: Manosanta desarrollo editorial.

Montoro-Gomez J., Á. (2000). La titularidad de derechos fundamentales por personas jurídicas (análisis de la jurisprudencia del Tribunal Constitucional Español). Cuestiones Constitucionales, 23-71.
Opinión Consultiva OC-22/16 (Corte Interamericana de Derechos Humanos 26 de Febrero de 2016).

Rey, F. (2014). Dignidad Humana. En E. MacGregor Ferrer, F. Ramírez Martínez, \& G. Mejía Figueroa, Diccionario de Derecho Procesal Constitucional y Convencional (págs. 592-595). Ciudad de México, México: Instituto de Investigaciones Jurídicas Universidad Nacional Autónoma de México.

Segado Fernandez, F. (1993). La teoría de los derechos fundamentales en la doctrina constitucional. Revista Española de Derecho Constitucional(39), 195-247

Segado Fernández, F. (1996). La dignidad de la persona como valor supremo del ordenamiento jurídico. Revista de la Facultad de Derecho de la Pontificia Universidad Católica del Perú(50), 11-45.

Sentencia BVerfGE, 7. 198 (Tribunal Constitucional Federal Alemán 15 de enero de 1958).

Sentencia RI-1343-2014 (Corte Suprema de Justicia de Honduras.- Sala de lo Constitucional 22 de abril de 2015).

VillalonCruz,P.(1989).Formaciónyevolución de los derechos fundamentales. Revista Española de Derecho Constitucional, 41.

Viñas Henríquez, M. (2017). ¿Derogación tácita o inaplicabilidad de preceptos legales preconstitucionales? Estudios Constitucionales, 307-328. 